\title{
Steroid responsiveness of peripheral blood T cells derived from steroid sensitive, steroid dependent, and steroid resistant asthmatics, and induction of steroid resistance by costimulatory signal
}

\author{
Akio Mori ${ }^{1 *}$, Akemi Abe ${ }^{1}$, Satoshi Kouyama ${ }^{1}$, Miyako Yamaguchi ${ }^{1}$, Yo lijima ${ }^{1}$, Chihiro Mitsui ${ }^{1}$, Chiyako Oshikata ${ }^{1}$, \\ Hidenori Tanimoto ${ }^{1}$, Kiyoshi Sekiya ${ }^{1}$, Takahiro Tsuburai ${ }^{1}$, Masami Taniguchi ${ }^{1}$, Mamoru Ohtomo ${ }^{1}$, Yuji Maeda ${ }^{1}$, \\ Maki Hasegawa', Kazuo Akiyama', Takayuki Ohtomo², Osamu Kaminuma ${ }^{3}$ \\ From EAACI International Severe Asthma Forum (ISAF 2012) \\ Gothenburg, Sweden. 11-13 October 2012
}

\section{Background}

Severe asthmatics are characterized by low responsiveness to inhaled corticosteroid (ICS) compared to mild asthmatics. Steroid resistance has been ascribed to various cell types including $\mathrm{T}$ cells, mononuclear cells, bronchial smooth muscle cells, etc.

\section{Method}

Peripheral blood mononuclear cells (PBMC) obtained from mild (steroid sensitive, SS), steroid dependent (SD), and steroid resistant (SR) asthmatics were stimulated with either mitogens or allergens. Effects of glucocorticoids (GCs) on the proliferation and cytokine synthesis were analyzed. Der $\mathrm{f} 2$-specific Th clones were established from PBMC by the limiting dilution.

\section{Results}

IL-5 production by PBMC of SS asthmatics was significantly reduced after ICS administration, but that of SD asthma remained high. $\mathrm{IC}_{50}$ values of dexamethasone suppression on cytokine synthesis and proliferation was not statistically different among SS, SD, or SR asthmatics. Addition of CD28 signal made proliferation of anti-CD3-stimulated Th clones steroid-resistant. The induction of steroid resistance was dependent on IL-2 receptor signal and PI-3 kinase activity.

\section{Conclusion}

Besides $\mathrm{T}$ cell intrinsic mechanisms, steroid responsiveness of $\mathrm{T}$ cells seems to be determined by the microenvironment, costimulatory signals and cytokines. Costimulatory signal might be involved in the induction of steroid resistance in T cells of SD asthma. The notion is consistent with our recent finding that administration of CTLA4-Ig made SR asthma model SS.

\section{Author details}

${ }^{1}$ National Hospital Organization, Sagamihara National Hospital, Clinical Research Center, Japan. ${ }^{2}$ Tokyo University of Pharmacy and Life Science, Department of Pharmacotherapeutics, Japan. ${ }^{3}$ The Tokyo Metropolitan Institute of Medical Science, Department of Allergy and Immunology, Japan.

Published: 3 May 2013

doi:10.1186/2045-7022-3-S1-P5

Cite this article as: Mori et al: Steroid responsiveness of peripheral blood T cells derived from steroid sensitive, steroid dependent, and steroid resistant asthmatics, and induction of steroid resistance by costimulatory signal. Clinical and Translational Allergy 2013 3(Suppl 1):P5.

'National Hospital Organization, Sagamihara National Hospital, Clinical

Research Center, Japan

Full list of author information is available at the end of the article

( 2013 Mori et al; licensee BioMed Central Ltd. This is an Open Access article distributed under the terms of the Creative Commons Attribution License (http://creativecommons.org/licenses/by/2.0), which permits unrestricted use, distribution, and reproduction in any medium, provided the original work is properly cited. 